ORIGINAL ARTICLE

\title{
Effect of urban closed circuit television on assault injury and violence detection
}

\author{
V Sivarajasingam, J P Shepherd, K Matthews
}

Injury Prevention 2003;9:312-316

\begin{abstract}
Objective: To evaluate the effect of closed circuit television (CCTV) surveillance on levels of assault injury and violence detection.

Design: Intervention versus control study design.

Setting: Five town/cities with CCTV surveillance and five, matched control centres without CCTV surveillance in England.

Intervention: CCTV installation and surveillance.

Methods: Assault related emergency department attendances and violent offences recorded by the police in CCTV and control centres in the four years, 1995-99, two years before and two years after CCTV installation, were compared.

Results: Assault related emergency department attendances decreased in intervention centres $13 \%$ decrease, ratio 0.96 ; $95 \%$ confidence interval $(\mathrm{Cl}) 0.93$ to 0.99 ) and increased in control centres $(11 \%$ increase, ratio $1.11 ; 95 \% \mathrm{Cl} 1.08$ to 1.14). Overall, changes in emergency department assault attendance in CCTV and control centres were significantly different $(t$ test, $\mathrm{p}<0.05)$. Police recorded violence increased in CCTV (1 1\% increase, ratio 1.16; $95 \% \mathrm{Cl} 1.08$ to 1.24 ) and control centres (5\% increase, ratio $1.06 ; 95 \% \mathrm{Cl} 0.99$ to 1.13). Overall, changes in police recording in CCTV and control centres were not significantly different ( $t$ test, $p>0.05$ ). In CCTV centres, decreases in assault related emergency department attendances and increases in police violence detection were not uniform.

Conclusion: CCTV surveillance was associated with increased police detection of violence and reductions in injury or severity of injury. CCTV centre variation deserves further study.
\end{abstract}

See end of article for authors' affiliations

Correspondence to:

Dr Vaseekaran

Sivarajasingam,

Department of Oral

Surgery, Medicine and

V iolence is a major cause of physical and psychological injury, deformity, disability, and premature death. Prevention of violence related morbidity and mortality has become an important public health issue in many countries. ${ }^{1}$ In the past decade there has been a proliferation of closed circuit television (CCTV) in public and private settings, including town centres, with the United Kingdom boasting the most extensive CCTV surveillance of public spaces in the world. ${ }^{2}$ This has resulted from initiatives by local and central government, funded in part by the European Community, local authorities, and businesses. A goal of CCTV surveillance is the prevention of crime (that is, personal and property) and disorder but there is little evidence of this effect, except in relation to acquisitive crime like theft and car crime. ${ }^{3}$ A recent systematic review on the crime prevention effects of CCTV included 18 evaluations and concluded that CCTV reduces crime to a small degree. ${ }^{4}$ An important unanswered question is whether CCTV is effective in preventing town/city centre violence. We carried out a study to evaluate the effect of CCTV systems on violence detection and assault injury in town/city centres in England.

\section{METHODS}

In this study, a focus of interest was the possible differential effect of CCTV on police and emergency department measures of violence, since police records reflect the detection of offences whereas emergency department records reflect treatment. It is known that treatment for assault injuries is provided predominantly by emergency departments. ${ }^{5}$ It was hypothesised that CCTV might increase police detection of assaults and that early detection of precursors to violence (for example, arguments) by CCTV might limit injury. This would be expected to decrease violence related emergency department attendance. Importantly for a deterrent effect, however, potential assailants must be aware of the presence of factors that increase the chances of detection, ${ }^{6}$ and many assailants/ protagonists, often through intoxication, are unlikely to be aware of the presence of CCTV surveillance. ${ }^{7}$

To test these hypotheses, it was necessary to study numbers of violent offences and numbers of those injured in violence treated in emergency departments. Ideally, comparisons of offences and injuries in precise locations covered by CCTV surveillance versus those not covered by CCTV surveillance were necessary. However, the known concentration of violence in a few urban centre streets with large numbers of licensed premises provided justification for comparing total emergency department assault related attendances with total violent offences. ${ }^{5}$ In England, emergency departments are situated either within or in very close proximity of town and city centres. Also, installation of public space CCTV is concentrated in urban centre entertainment areas where the night time economy is concentrated and population dynamics are high. Therefore almost all persons sustaining assault injury requiring treatment within these centres would have attended the single emergency department serving the town/city and any effect on assault injury and violence detection after CCTV installation would be expected to become apparent. This proxy measure of public urban centre violence was also justified because other categories of violence, such as domestic violence, workplace violence, and violence inside licensed premises would not be expected to be affected by public space CCTV. Furthermore, the use of non-CCTV comparison centres would reduce the contributions of these and other potential confounding

Abbreviations: CCTV, closed circuit television; $\mathrm{Cl}$, confidence interval 


\begin{tabular}{llll}
\multicolumn{2}{l}{ Table $1 \quad$ Intervention and control centres } & & \\
\hline $\begin{array}{l}\text { Intervention centres (CCTV } \\
\text { installation date) }\end{array}$ & Data collection period & Control centres & Data collection period \\
\hline Ashford (May 1997) & May 1995-April 1999 & Derby & May 1995-April 1999 \\
Eastbourne (July 1997) & July 1995-June 1999 & Huntingdon & May 1995-April 1999 \\
Lincoln (March 1997) & March 1995-Feb 1999 & Poole & May 1995-April 1999 \\
Newport (July 1997) & July 1995-June 1999 & Chelmsford & May 1995-April 1999 \\
Peterborough (April 1997) & April 1995-Mar 1999 & Scarborough & May 1995-April 1999 \\
\hline CCTV, closed circuit television. & & &
\end{tabular}

factors. Unfortunately, the extent of CCTV surveillance in England did not allow a randomised trial.

Five towns/cities (Ashford, Eastbourne, Lincoln, Newport (Isle of Wight), and Peterborough) with street CCTV installed between March and July 1997 were selected from a sample frame $(\mathrm{n}=56)$ of CCTV towns/cities in England, obtained from the National CCTV Users Group. This group comprised towns and cities with street CCTV installed for the purpose of reducing crime. CCTVs in all five centres were operational 24 hours a day. Selection of control town/city centres was more difficult as large and increasing numbers of towns and cities in England had CCTV cameras installed within their centres as part of crime reduction programmes. Five control towns/cities (Chelmsford, Poole, Derby, Scarborough, and Huntingdon) without CCTV were selected randomly from the same geographical region and with approximately the same population but which were not included in the National CCTV Users Group list. The absence of CCTV was confirmed by telephone calls to local council and police. During this selection process three towns/cities not included in the National CCTV Users Group list were found to have CCTV installed within their centres and were excluded. Data were available from all centres and all emergency departments categorised attendances according to cause of injury so that all assault related attendances could be identified. First point of patient contact was with triage personnel, before registration by receptionists. It is usually at this stage that the reason for attendance (assault in this study) is entered into emergency department computer records. Patients were then referred to the emergency department medical officer and to specialists if required. The outcomes were discharge without further review, discharge with review in an outpatient department, or admission. For every new incident a new record was created. Emergency department recorded assault data in this study were retrieved locally without individual patient identifiers. Violent offences data relating to assault and wounding which occurred in city centre police beat areas were also collated locally by police personnel and disclosed without confidential information. Numbers of violence related emergency department attendances and violent offences over a period of four years were compared: two years before and two years after CCTV installation (table 1).

In the five intervention town/cities, CCTV surveillance was undertaken by the local council in four (Ashford, Lincoln, Newport, and Peterborough) centres and by police in one (Eastbourne). In the four council controlled CCTV systems links with the police comprised a dedicated telephone line in the CCTV control room and a video monitor at the police station. CCTV operators observed the areas covered and information on assaults and precursors to assaults was relayed to police personnel. Any action taken based on the information relayed rested solely with the police. Action involved directing foot and/or vehicle patrols to the incident site.

\section{Data analysis}

Scatter diagrams with quarterly moving averages were used to plot emergency department and police recorded violence data for all 10 centres over the four year period. The Student's $t$ test was used to compare changes in violence before and after CCTV installation. Injury and violent crime data for the first two years were compared with injury and violence data for the last two years (table 2). Lack of co-terminosity between areas served by emergency departments and police command units did not justify comparison of emergency department and police data.

\section{RESULTS}

Overall, CCTV installation was associated with a significant decrease in numbers of those reporting injury in assault at emergency departments $(-3 \%$, ratio $0.96,95 \%$ confidence interval (CI) 0.93 to 0.99 ) and was associated with a significant ( $11 \%$, ratio 1.16 ; $95 \%$ CI 1.08 to 1.24 ) increase in violent offences recorded by the police (table 2). In

Table 2 Emergency department and police recorded violence in CCTV and control towns

\begin{tabular}{|c|c|c|c|c|c|c|c|c|c|c|}
\hline & \multicolumn{2}{|c|}{ Emergency department } & \multirow[b]{2}{*}{ Ratio } & \multirow[b]{2}{*}{$95 \% \mathrm{Cl}$} & \multirow[b]{2}{*}{ Significance } & \multicolumn{2}{|l|}{ Police } & \multirow[b]{2}{*}{ Ratio } & \multirow[b]{2}{*}{$95 \% \mathrm{Cl}$} & \multirow[b]{2}{*}{ Significance } \\
\hline & Before CCTV & After CCTV & & & & Before CCTV & After CCTV & & & \\
\hline \multicolumn{11}{|l|}{ CCTV centres } \\
\hline Ashford & 1050 & 1093 & 1.04 & 0.95 to 1.13 & & 213 & 201 & 0.94 & 0.77 to 1.14 & \\
\hline Eastbourne & 1602 & 1479 & 0.92 & 0.86 to 0.99 & $\downarrow$ & 245 & 400 & 1.63 & 1.39 to 1.91 & $\uparrow$ \\
\hline Lincoln & 3097 & 3283 & 1.06 & 1 to 1.11 & $\uparrow$ & 412 & 457 & 1.10 & 0.97 to 1.26 & \\
\hline Newport & 1183 & 1077 & 0.91 & 0.83 to 0.98 & $\downarrow$ & 274 & 255 & 0.93 & 0.78 to 1.1 & \\
\hline Peterborough & 1262 & 991 & 0.78 & 0.72 to 0.85 & $\downarrow$ & 485 & 579 & 1.19 & 1.05 to 1.34 & $\uparrow$ \\
\hline Aggregate & 8194 & 7923 & 0.96 & 0.93 to 0.99 & $\downarrow$ & 1629 & 1892 & 1.16 & 1.08 to 1.24 & $\uparrow$ \\
\hline \multicolumn{11}{|l|}{ Control centres } \\
\hline Chelmsford & 1761 & 2044 & 1.16 & 1.08 to 1.23 & $\uparrow$ & 299 & 355 & 1.18 & 1.01 to 1.38 & $\uparrow$ \\
\hline Poole & 1470 & 1388 & 0.94 & 0.87 to 1.01 & & 352 & 328 & 0.93 & 0.80 to 1.08 & \\
\hline Derby & 4704 & 5093 & 1.08 & 1.04 to 1.12 & $\uparrow$ & 867 & 928 & 1.07 & 0.97 to 1.17 & \\
\hline Scarborough & 1046 & 1242 & 1.18 & 1.09 to 1.28 & $\uparrow$ & 169 & 200 & 1.18 & 0.96 to 1.45 & \\
\hline Huntingdon & 743 & 1050 & 1.41 & 1.28 to 1.55 & $\uparrow$ & 83 & 69 & 0.83 & 0.60 to 1.14 & \\
\hline Aggregate & 9724 & 10817 & 1.11 & 1.08 to 1.14 & $\uparrow$ & 1770 & 1880 & 1.06 & 0.99 to 1.13 & \\
\hline
\end{tabular}




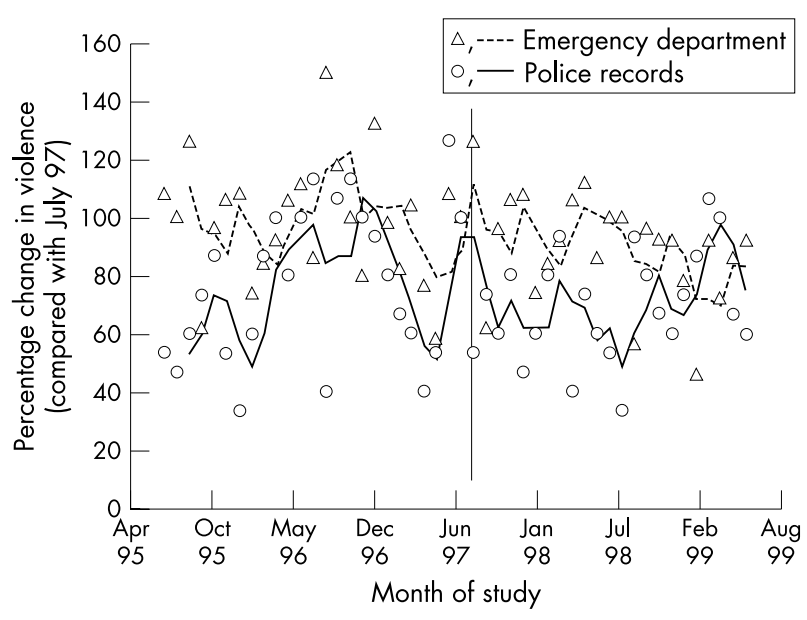

Figure 1 Trends in recorded violence in Newport, Isle of Wight (intervention centre) showing the three month moving averages for emergency department injury and police violence records. Vertical line indicates month of CCTV installation.

contrast, in the control centres overall, there was a significant increase in assault related emergency department attendance ( $11 \%$, ratio $1.11 ; 95 \%$ CI 1.08 to 1.14 ) but no significant change in violence recorded by the police $(5 \%$, ratio $1.06 ; 95 \%$ CI 0.99 to 1.13). The change in assault attendance at emergency departments in CCTV towns was significantly different from change in emergency department attendance in control centres (3\% decrease compared with $11 \%$ increase, $t$ test, $\mathrm{p}<0.05)$. The change in police recorded violence in CCTV centres was not significantly different from police recorded violence in control centres ( $11 \%$ increase compared with $5 \%$ increase, $t$ test, $\mathrm{p}>0.05)$. Changes in CCTV centres were not uniform (figs 1 to 5 ).

\section{Control centres}

In four of five control centres (Chelmsford, Derby, Huntingdon, and Scarborough) there were significantly more assault related injury emergency department attendances in the last two years (1997-99) compared with the first two years (1995-97) (table 2). Assault related emergency department attendances in Poole did not change significantly over the four year period (table 2). In one of five control centres (Chelmsford) there were significantly more violent offences

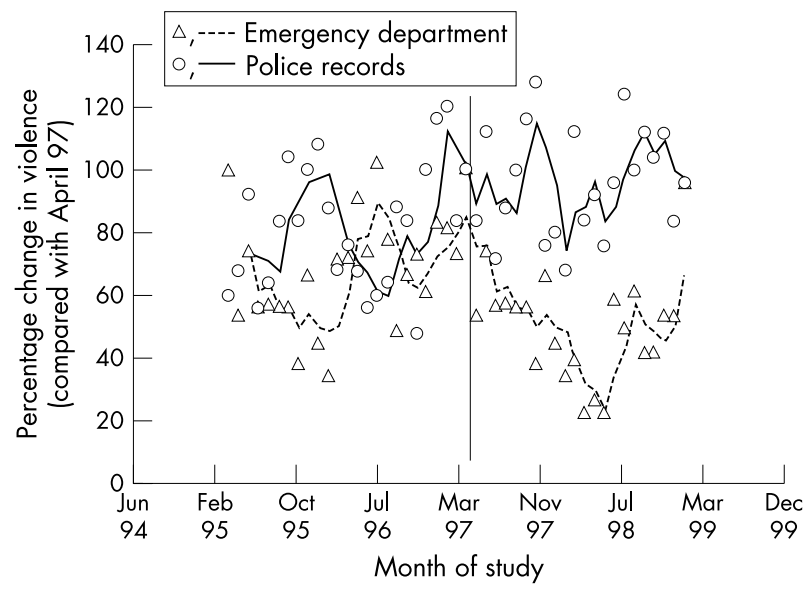

Figure 2 Trends in recorded violence in Peterborough (intervention centre) showing three month moving averages for emergency department injury and police violence records. Vertical line indicates month of CCTV installation.

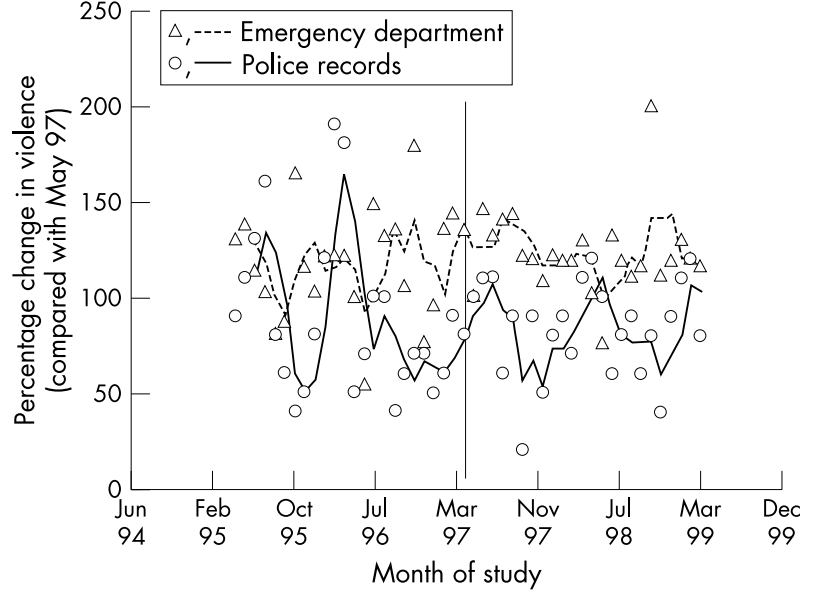

Figure 3 Trends in recorded violence in Ashford (intervention centre) showing three month moving averages for emergency department injury and police violence records. Vertical line indicates month of CCTV installation.

recorded by the police in the last two years (1997-99) compared with the first two years (1995-97) of the study (table 2). In four control centres no significant change in police recording was observed.

\section{Intervention centres}

CCTV installation was associated with a significant reduction in assault related emergency department attendance in Newport, Peterborough, and Eastbourne (figs 1, 2, and 5) and a significant increase in Lincoln (fig 4). In contrast, there were significant increases in violence detected by the police in Peterborough and Eastbourne (figs 2 and 5) but no significant decreases (table 2). There were differences in the pattern of reduction in violence related injury after CCTV installation. For example, in Newport, reduction in assault related attendance appears to be gradual over the two year period after CCTV installation. In Peterborough reduction in emergency department attendance appeared to take place only during the first year after CCTV installation and was followed by an increase in emergency department recorded attendance.

There were also differences in the pattern of increase in violence recorded by police after CCTV installation. For example, in Eastbourne an increase was observed approximately six months before CCTV became operational and in Peterborough a gradual increase was observed after CCTV installation.

\section{DISCUSSION}

The main findings in this study were that CCTV was associated with increased police detection of violence but reduced emergency department treatment. As most violence is known to be concentrated in relatively few streets within town and city centres, ${ }^{6}$ this study would have been expected to identify any clear changes in the incidence of violence and injury consequent upon CCTV installation. If there had been a significant deterrent effect as a result of CCTV installation then a decline in police detection of violence rather than the noted increase would have occurred. This study provides no evidence of a deterrent effect.

A number of important methodological factors distinguish this study from previous evaluations of the effect of CCTV. Firstly, this study focused on both health services (emergency department) and police data. Secondly the study was carried out over a four year period in contrast to previous studies in which before and after periods were either too short- 


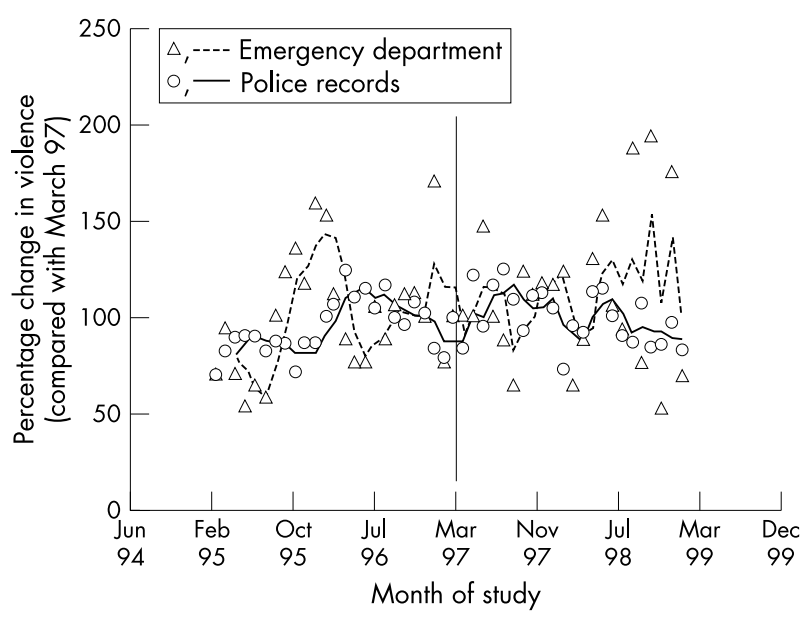

Figure 4 Trends in recorded violence in Lincoln (intervention centre) showing three month moving averages for emergency department injury and police violence records. Vertical line indicates month of CCTV installation.

typically, three months before and after installation-or even of periods of unequal length. ${ }^{8}$ Thirdly, this study was concerned only with the effect of CCTV on violent crime and assault injury: in the majority of CCTV studies, different categories (violence, theft, public order) of crime have been grouped together concealing possible increases in some categories and decreases in others. ${ }^{9}$ Given the limited number of town and city centres without CCTV in England and Wales at the time of study, close matching of CCTV and control centres was not possible. However, the selection process resulted in the best possible match of CCTV and five control centres.

Theoretically, CCTV may act via a variety of mechanisms on violent crime. Perpetrators may be detected, and removed; CCTV may deter potential offenders who perceive an increased risk of detection; CCTV may direct security personnel to locations where precursors to offending have been detected, which may head off their translation into crime and/or reduce the severity of harm; CCTV could symbolise efforts to take crime seriously, and the perception of those efforts may both energise law abiding citizens and/or deter crime. The presence of CCTV may induce people to take elementary security precautions, for fear that they will be shamed by being shown on CCTV. ${ }^{10}$

Overall, emergency department data suggested that CCTV surveillance significantly limited injury sustained in public space violence in town/city centres which would otherwise have been sustained if CCTV had not been installed. In contrast, CCTV installation was associated with increases in police detection. This finding exemplifies the inappropriateness of measures of violence based only on police recordingwhich continue to be prominently and misleadingly published.

Differences in the pattern of decrease in violence related attendances in Newport and Peterborough emergency departments suggest that there were local differences in police responses to CCTV surveillance. The rapid decline in violence related injury in Peterborough during the first year after installation could reflect greater vigilance by CCTV operators in Peterborough or increased or accelerated police responsiveness to incidents. This interpretation fits with a significant increase in police recorded violence in Peterborough over the same period. However, the rapid fall in violence related emergency department attendances in Peterborough after CCTV installation was not maintained

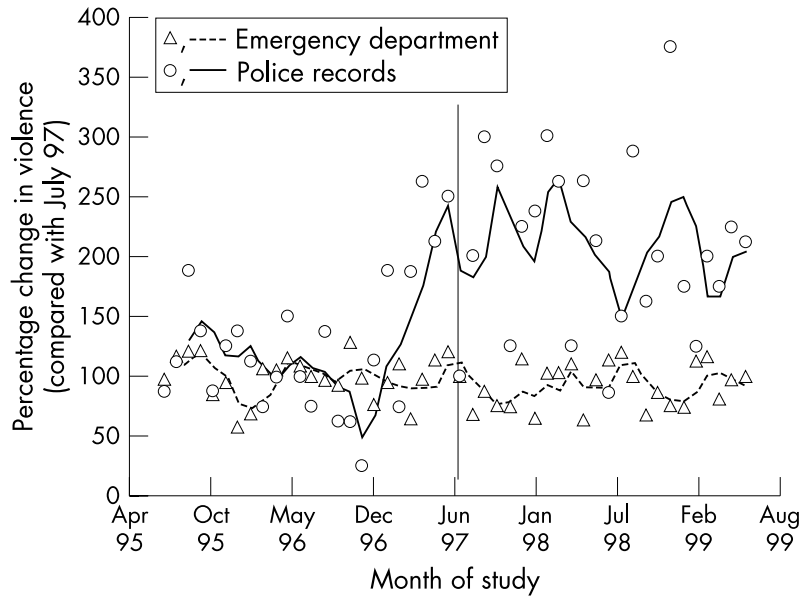

Figure 5 Trends in recorded violence in Eastbourne (intervention centre) showing three month moving averages for emergency department injury and police violence records. Vertical line indicates month of CCTV installation.

after the first year, perhaps through deteriorating CCTV ascertainment, communication of CCTV derived information to patrol police officers, or through inaction. In four of the five control centres (Chelmsford, Derby, Huntingdon, and Scarborough) there were significant increases in emergency department assault attendances, with Poole showing no significant change over the study period. There were substantial individual centre differences, with significant increases in two centres (Eastbourne and Peterborough) and no significant change in three centres (Ashford, Lincoln, and Newport). There were no significant reductions in police recorded violence in any of the control centres.

Previous injury research suggests a mechanism for the differential effect on emergency department and police measures of violence observed in this study. In a prospective study of 539 adult victims of assault attending a major city centre emergency department it was found that, overall, severe injury was progressively more likely as the reported number of blows increased and that most assaults were preceded by an argument/dispute. ${ }^{11}$ Increased surveillance by means of CCTV and the opportunity for prompt police action may therefore explain the apparently conflicting results of this study: the benefit of CCTV might lie less in preventing such offences (which it is argued will occur anyway because of their impulsive nature and the role of alcohol), but more in facilitating a faster police response to arguments or assaults in public spaces, which limits their duration and therefore reduces the incidence and seriousness of injury. Overall, the results of this study provide evidence which supports the

\section{Key points}

- Public space CCTV surveillance was associated with increased police detection of violence.

- Public space CCTV surveillance was associated with reduction in numbers of people injured in assault who were treated at emergency departments.

- Impact of CCTV on police detection and assault injury was not uniform across intervention towns and cities.

- Effectiveness of CCTV lies less in preventing assaults and their precursors, but more in preventing injury through increased police detection and intervention. 
utility of CCTV in terms of harm reduction and as a prompt to police action, but does not support its utility as a violence deterrent.

This study has demonstrated individual town/city centre differences in the effects of CCTV. Differences in the proportion of public space covered by cameras, lighting within the city centre, vigilance of CCTV operators, and police responsiveness are some of the factors that may account for these differences. Further multicentre studies in which local authority and police scrutiny and responsiveness are studied are an important priority in the identification of explanatory factors. This study provides evidence that emergency department data should be developed as a measure of community violence related injury and of the effectiveness of CCTV and police services. It also highlights the disadvantages of simplistic, uncontrolled research methodology in criminological intervention studies and the serious shortcomings of police crime data as a measure of violence.

\section{ACKNOWLEDGEMENTS}

We thank Robert Newcombe for statistical advice and emergency department and police managers for data sharing.

\section{Authors' affiliations}

V Sivarajasingam, J P Shepherd, Department of Oral Surgery, Medicine and Pathology, Violence Research Group, University of Wales College of Medicine, Cardiff, UK

K Matthews, Cardiff Business School, Cardiff, UK

\section{REFERENCES}

1 Shepherd JP. Tackling violence. BMJ 1998;316:879.

2 Short E, Ditton J. Does closed circuit television prevent crime? CCTV Today 1995:2:10-12.

3 Tilley N. Understanding car parks, crime and CCTV: evaluation lessons from safer cities. Home Office police research group crime prevention unit series. Paper 42. London: Home Office, 1993.

4 Welsh BC, Farrington DP. Crime prevention effects of closed circuit television: a systematic review. London: Home Office Research Study 252, 2002.

5 Shepherd JP, Brickley MR. Alcohol intoxication, stressors and injury in urban violence. Br J Criminol 1996;36:546-66.

6 Von Hirsch A, Bottoms AE, Burney E, et al. Criminal deterrence and sentence severity: an analysis of recent research. Oxford: Hart Publishing, 1999.

7 Shepherd JP. Emergency room research on links between alcohol and violent injury. Addiction 1998;93:1261-2.

8 Brown B. CCTV in town centres: three case studies. Police Research Group Crime Detection and Prevention Series. Paper 68. London: Home Office, 1995.

9 Ditton J, Short E. When open street CCTV appears to reduce crime: does it just get displaced elsewhere? CCTV Today 1998;5:13-16.

10 Armitage R, Smyth G, Pease K. Burnley CCTV evaluation. In: Painter K, Tilley N, eds. Surveillance of public spaces: CCTV, street lighting and crime prevention. Vol 10. Crime prevention studies. Monsey, NY: Criminal Justice Press, 225-50.

11 Shepherd JP, Shapland M, Pearce NX, et al. Pattern, severity and aetiology of injuries in victims of assault. J $R$ Soc Med 1990;83:75-9.

\section{LACUNAE}

\section{Call for tough ATV laws}

Doctors and public health officials in New Mexico have warned about the dangers of allterrain vehicles (ATVs) and called for laws ranging from mandatory ATV training to an outright ban on kids driving the machines. In New Mexico, ATVs are largely unregulated. Children of any age can legally drive ATVs built for adults and are not required to wear helmets or eye protection. A child helmet law, eye protection law, and passenger limit law are on the books in New Mexico-but they apply only to motorcycles and to three wheeler ATVs, which have been out of production for well over a decade. The ATV industry itself supports mandatory ATV safety training for all drivers, a mandatory helmet law, and age restrictions that would keep children off adult sized ATVs (contributed by Les Fisher; from the Albuquerque Journal, July 2003).

\section{Flying underpants cause crash}

Reuters report that a pair of flying underpants caused a crash on a German highway when they landed on a driver's face and blocked his view, police said Tuesday. A police spokesman in the central town of Gotha said one of a group of naked men in a van threw the underwear into a Volkswagen Passat as they passed it on a busy stretch of one of Germany's notoriously speedy autobahns. "The underpants landed on the driver's face, causing him to ram the truck ahead from behind", said the spokesman, adding that he did not know why the men were driving along naked. No one was hurt in the crash, but police are hunting the owner of the underpants for failing to stop at the scene (contributed by Ian Scott; from the CNN Europe website). 